\title{
ANALISIS ULANG STABILITAS TANAH DENGAN COMPACTED LATERITIC SOIL COLUMNS PADA COLLAPSIBLE SOIL
}

\author{
Antonius Kristanto ${ }^{1}$ dan Gregorius Sandjaja Sentosa ${ }^{2}$ \\ ${ }^{1}$ Program Studi Sarjana Teknik Sipil, Universitas Tarumanagara, Jl. Letjen S. Parman No.1 Jakarta \\ Antonius.325130033@stu.untar.ac.id \\ ${ }^{2}$ Program Studi Sarjana Teknik Sipil, Universitas Tarumanagara, J1. Letjen S. Parman No.1 Jakarta \\ gregorius@ft.untar.ac.id
}

\begin{abstract}
Indonesia is a tropical country that has very high rainfall rate in the whole year. This is very difficult to overcome with land problems that exist in Indonesia. The condition of the land which has a very not stable soil or we can say that it has collapsible status. Land that has collapse problems is prone to landslides, which involves very low soil carrying capacity and also very high water content in the soil. Many methods can be used to reduce collapsible soi lrate. In this re-analysis we calculate the problem of soil using the lateritic compacted soil columns. This process uses the formation of soil columns by compressing a number of points with a certain diameter so that the carrying capacity of the soil in order to repair and improve minimum occurrence of collapsible soil. But this method has advantages and disadvantages. From the results of the re-analysis conducted it was proven that the stability method using Compacted Lateritic Soil Colums reduced the possibility of soil experiencing collapsible soil. The analysis shows that the value of the edge of displacement or the total decreases due to the stability used using Compacted Lateritic Soil Colums.
\end{abstract}

Keywords: collapsible soil; compacted lateritic soil colums; landslide; edge of displacement; soil stability

\begin{abstract}
ABSTRAK
Indonesia adalah negara tropis yang memiliki curah hujan yang sangat tinggi. Hal tersebut sangat berpengaruh dengan keadaan stabilitas tanah yang berada di Indonesia. Keadaan tanah yang memiliki stabilitas yang sangat tidak stabil dapat juga di sebut tanah dengan keadaan status collapsible. Tanah yang memiliki keadaan collapsible memiliki rentan mengalami longsor, di akibatkan daya dukung tanah yang sangat rendah dan juga kadar air yang sangat tinggi di dalam kandungan tanah. Banyak metode stabilitas yang dapat dilakukan untuk mengurangi kemungkinan terjadinya collapsible soil. Pada analisis ulang perhitunga ini membahas stabilitas tanah menggunakanan Compacted Lateritic Soil Colums.Proses stabilitas ini menggunakan cara pebentukan kolom tanah dengan memadatkan bebarapa titik dengan diameter tertentu agar daya dukung tanah mengalami peningkatan dan mencegah terjadinya collapsible soil. Tetapi metode ini memiliki kelebihan dan juga kekurangan. Dari hasil analisi ulang yang dilakukan terbukti bahwa metode stabilitas menggunakan Compacted Lateritic Soil Colums mengurangi kemungkinan terjadinya tanah mengalami Collapsible soil. Dalam Analisis terlihat nilai edge of displacement atau total penurunan yang terjadi berkurang diakibatkan stabilitas yang di gunakan menggunakan Compacted Lateritic Soil Colums.
\end{abstract}

Kata kunci: collapsible soil; compacted lateritic soil colums; tanah longsor; edge of displacement; stabilisasi tanah

\section{PENDAHULUAN}

Pada pembangunan yang di lakukan daerah pegunungan atau perbukitan, tanah longsor adalah salah satu masalah yang sering paling sering terjadi, terutama pada daerah lereng yang memiliki curah hujan yang terhitung tinggi. Berdasarkan data Badan Nasional Penanggulangan Bencana ( BNPB), selama tahun 2019 telah terjadi 1.586 Kejadian Bencana Menyebabkan 438 Jiwa Meninggal dan Hilang Terjadi Selama Tahun 2019 akibat tanah longsor. Menurut Kepala Pusat Data, Informasi, dan Humas BNPB Sutopo Purwo Nugroho di kantornya, J1 Pramuka Raya, Jakarta Timur, Rabu (2/1/2019), terdapat 274 kabupaten/ kota di Indonesia yang rawan longsor dengan jumlah penduduk yang tinggal di daerah rawan longsor dengan jumlah penduduk yang tingal di daerah 
longsor sebanyak 40,9 juta jiwa (Detik.com, 2019). Dari data tersebut dapat di lihat bahwa dampak yang di timbulkan akibat bencana longsor cukup fatal.

Tanah yang berpotensi longsor dapat diidentifikasi dengan uji di laboratorium. Di Indonesia yang kebanyakan merupakan daerah pegunungan dan perbukitan, penelitian untuk collapsible soil masih jarang dilakukan untuk mengetahui tingkat kerawanan dari suatu lereng. Salah satu uji laboratorium yang dapat digunakan adalah mengunakan alat uji konsolidasi. Dari pengujian ini dapat diketahui seberapa besar potensi kolaps (collapse potential). Pemilihan topik ini dikarenakan secara keseluruhan penelitian yang di lakukan oleh saudara Jono Syafei (2017), yang memeliti collapsible soil dengan variant $95 \%$ dan 98\% kepadatan kering. Analisis ini menguji persentase terjadinya collapsible soil jika tanah diperbaiki dengan cara menambahkan Compacted Lateritic Soil Columns yang di teliti oleh (Pereira, Mara Sarro, 2019) dan di banding kan dengan sample parameter tanah yang di dapat dari data yang di gunakan sebagai pebanding. Dan juga saudara Surachri (2018) yang membahas tentang, analisis penurunan tanah dengan menggunakan geotekstil pada lapisan tanah, untuk memperbaiki struktur utama dari lapisan tanah tersebut untuk mencegah terjadi nya collapsible soil.

\section{Collapsible soil}

Collapsible soil merupakan jenis tanah yang rentan mengalami penyusutan volume secara tiba-tiba dan ekstrim. Collapsible soil biasanya terjadi pada tanah dengan kondisi seperti:

- Tanah lepas (loose), cemented soil

- Tanah dengan kepadatan kering rendah

- Sensitivitas tinggi.

Tanah jenis ini biasanya merupakan tanah endapan, tanah yang sudah mengalami perpindahan dan mengalami siklus cuaca berkali-kali. Faktor yang memicu keurntuhan tanah biasanya disebabkan oleh beban yang bertambah, tanah mengalami perbasahan (biasanya dikarenakan oleh hujan), atau kombanasi dari keduanya. Pada saat beban bertambah, maka tegangan yang diterima tanah meningkat, dan ketika tanah mengalami pembahasan akan meningkatkan kejenuhan tanah dari tidak jenuh atau jenuh sebagian menjadi jenuh. Klasifikasi collapsible soil dapat dilihat pada gambar 1 .

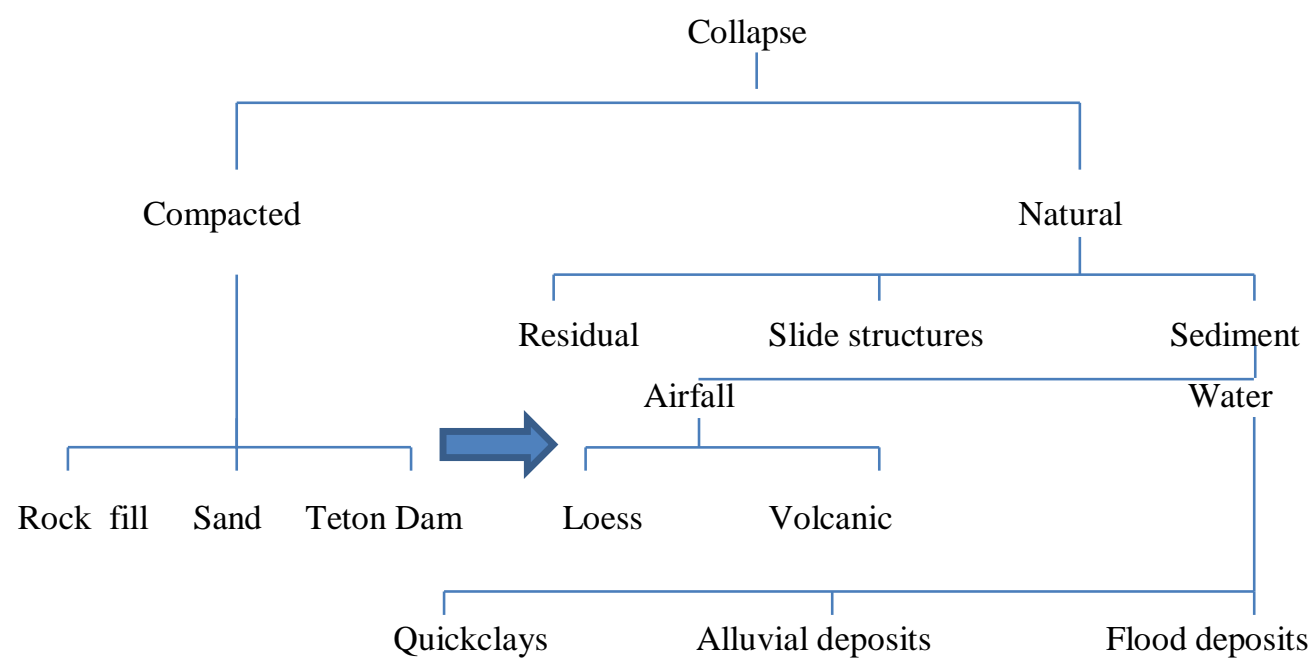

Gambar 1. Klasifikasi collapsible soil (Sumber: Kyle \& Rogers, 1995)

\section{Hubungan sifat fisik tanah dengan potensi keruntuhan}

Bedasarkan sifat fisik tanah, dapat dilihat seberapa besar potensi keruntuhannya. Ada 2 metode empiris yang dapat digunakan, antara lain :

- Hubungan antara kepadatan kering dan persentase butiran halus (lulus saringan no. 200), pada gambar 2. 


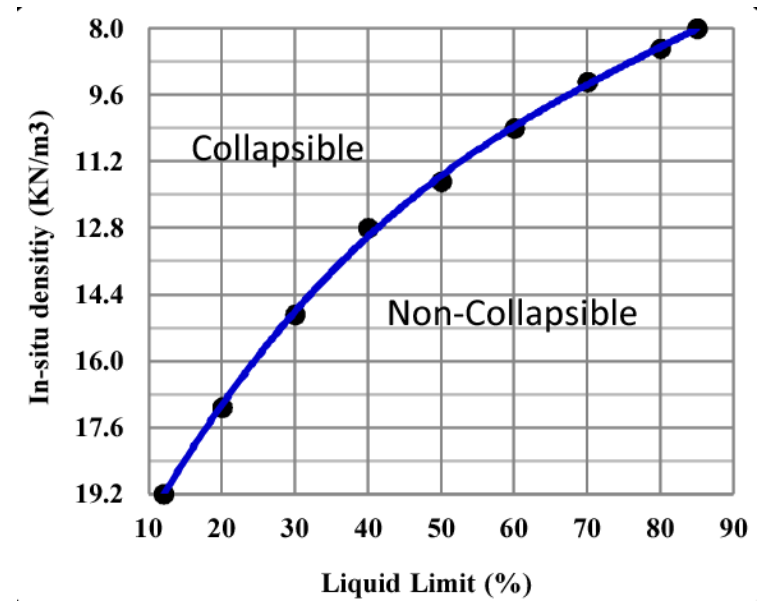

Gambar 2. Hubungan antara kepadatan kering dan presentase butiran halus (Sumber:Gibbs and Bara, 1962)

Pada gambar 2 dapat dilihat bahwa semakin besar persentanse jumlah butiran yang lolos saringan no. 200, maka kemungkinan tanah mengalami keruntuhan akan semakin kecil.

- Hubungan antara kepadatan kering dan batas cair untuk tanah stabil dan tidak stabil dapat dilihat pada gambar 3 .

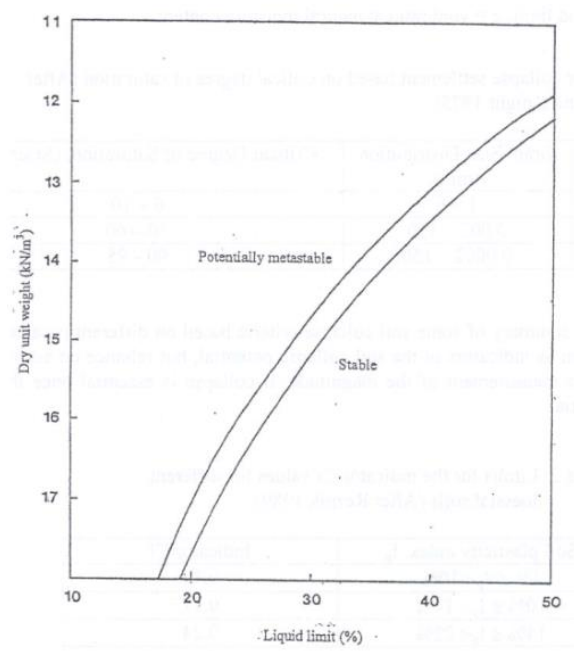

Gambar 3. Hubungan antara kepadatan kering dengan batas cair untuk tanah stabil dan tidak stabil (Sumber: Gibbs and Bara. 1962)

Pada gambar 3 dapat dilihat bahwa semakin tinggi batas cair (liquid limit) tanah tersebut maka kemungkinan terjadinya keruntuhan semakin kecil juga. Dalam mengindentifikasi keruntuhan pada tanah, dapat juga di lakukan pengetestan terhadap tanah menggunakan alat ukur odeometer pada lab untuk mendapatkan hasil grafik titik jenuh pada saat tanah mengalami fase collaps. Grafik collapsible soil dapat di lihat pada gambar 4. 


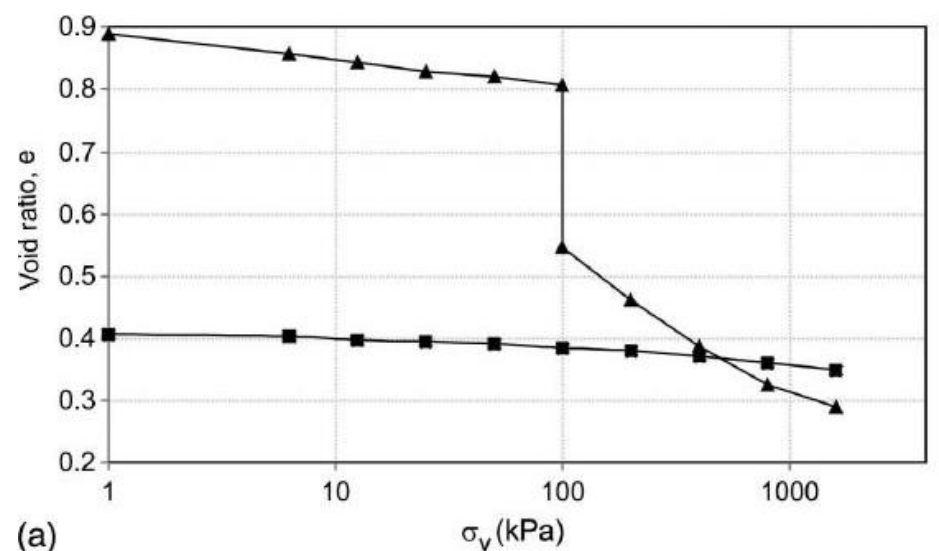

Gambar 4. Grafik collapsible soil pada test odeometer (Sumber: Pereira, 2019)

\section{Penggunaan rumus untuk mendapatkan edge of displacement}

Dalam Jurnal yang sudah di tentukan dapat di ambil sampel grafik qu untuk di ambil nilai tegangan dan nilai regangan agak dapat bisa mencari nilai modulus elastisitas dengan mengunakan rumus:

$$
E=\frac{\sigma}{e}
$$

Dengan $\mathrm{E}=$ Modulus of Elasticity (Modulus elastisitas), $\sigma=$ Stress (Tegangan), e = Axial Strain (Regangan).

Untuk mendapatkan modulus elastisitas komposit

$$
\overline{\mathrm{E}}=\frac{(80 \times E 1+20 \times E 2)}{100}
$$

Dengan $\overline{\mathrm{E}}=$ Modulus elastisitas Komposit, E1 = Modulus elastisitas Unreinforced, $\mathrm{E} 2=$ Modulus elastisitas Reinforced (Dipadatkan 2.5\%).

Jika kita subtsitusikan teganan

$$
\sigma=\frac{F}{A}
$$

Dengan $\sigma=$ Stress (Tegangan), $\mathrm{F}=$ Tensile Strength (Gaya Tarik Tanah), A = Initial Cross-sectional Area (Luas penampang).

dan rumus regangan

$$
e=\frac{\Delta L}{L}
$$

dengan $\mathrm{e}=$ Axial Strain (Regangan), $\Delta \mathrm{L}=$ Change in length (pertambahan panjang), $\mathrm{L}=$ Initial Length of specimen (Panjang awal).

$$
\mathrm{O}_{Z}=\frac{h}{a}
$$

dengan $\mathrm{O} z=$ Delta $\mathrm{z}, \mathrm{h}=$ Depth $($ Kedalaman $), \mathrm{a}=$ Radius $($ Jari-jari $)$.

Sesudah di dapatkan nilai Ȯz, selanjutnya di cari nilai edge of displacement (Poulos\&Davis,1974) dengan menggunakan rumus:

$$
\mathrm{Pe}=\frac{2 P \cdot a \cdot\left(1-\mathrm{\gamma}^{2}\right) x I e}{E}
$$

Dengan $\mathrm{Pe}=$ Edge of Displacement $($ Penurunan yang terjadi), $\mathrm{P}=$ Pressure $($ Tekanan), a $=$ Radius (Jari-jari), $\mathrm{\gamma}=$ Poisson Ratio (Diambil y=0.3), Ie = Influence Factor (Faktor yang berpengaruh), E = Elastic Module (Modulus elastisitas). 


\section{METODE PENELITIAN}

Berikut langkah-langkah penelitian dalam penulisan tulisan mulai dari tahap awal sampai selesai:

\section{Studi literatur}

Studi literatur Studi literatur dilakukan untuk mengetahui dan mengumpulkan dasar teori yang digunakan dalam penulisan tulisan. Literatur yang digunakan berasal dari jurnal, buku, prosiding, dan hasil penelitian yang sudah pernah dilakukan.

\section{Persiapan data}

Persiapan data pebanding dari jurnal yang di dapat sebagai pedoman analisis.

\section{Membandingkan nilai}

Perbandingan grafik qu yang di peroleh oleh jurnal yang digunakan sebagai pedoman untuk mencari nilai E pada tiap sampel.

\section{Simulasi analisis penurunan yang terjadi}

Simulasi penurunan menggunakanan rumus elastic. Setelah di dapatkan nilai modulus elastisitas (E) pada setiap grafik qu dilakukan simulasi pada perhitungan manual dengan rumus elastic agar mendapatkan analisis penurunan tanah dari setiap parameter menggunakan rumus edge of displacement Poulos (1974).

\section{Analisis akhir perhitungan penurunan}

Analisis hasil simulasi hasil dari simulasi akan di analisis bedasarkan perhitungan pada pemograman, sehingga kita dapat mengetahui pengaruh Compacted Lateritic Soil Columns pada stabilitas tanah potensi collapsible.

\section{Menarik kesimpulan}

Membuat kesimpulanPada tahap terakhir ini akan dilakukan penarikan kesimpulan dari analisis yang sudah dilakukan dan saran yang diperlukan.

\section{Diagram alir}

Diagram aliran penelitian dapat dilihat pada gambar 5 berikut:

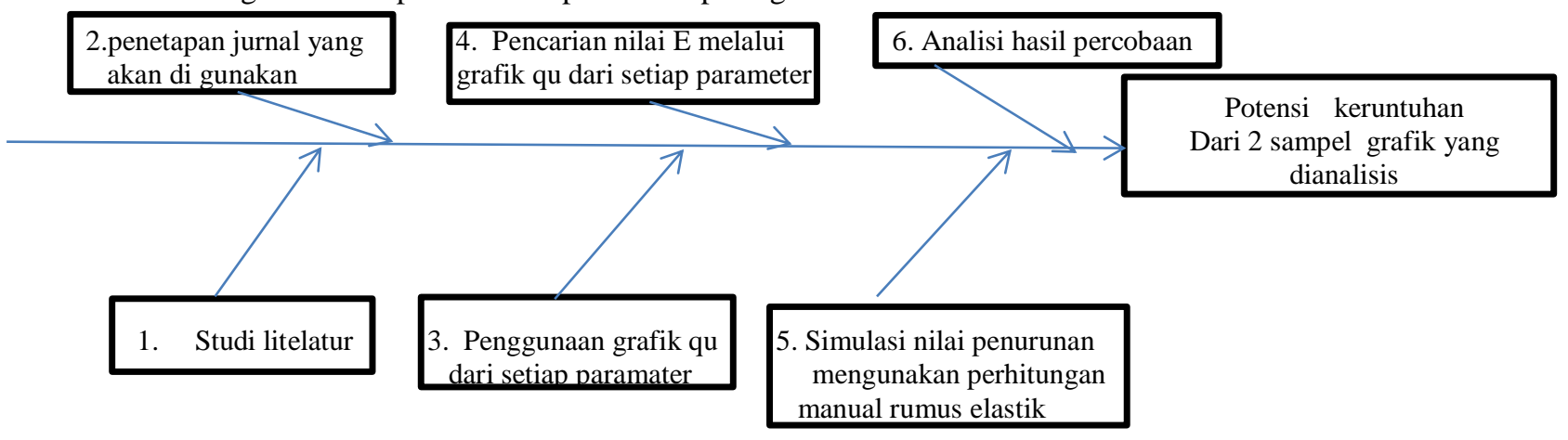

Gambar 5. Diagram alir penelitian

\section{Penetapan jurnal yang di gunakan}

Jurnal yang digunakan adalah jurnal yang berdujul Performance Evaluation of a Collapsible Soil Reinforced with Compacted Lateritic Soil Columns (Sumber: Pereira, Mara Sarro,. Eng., 2019) yang membahas tentang perbaikan stabilitas keadaan tanah yang bersifat metastable dan cenderung terjadi collapsible soil. Jenis perbaikan yang dilakukan pada jurnal ini adalah Compacted lateritic soil columns (penambahan kolom tanah padat).

\section{Perumusan nilai e}

Dari grafik di atas kita dapatkan nilai E dan $\sigma$ pada tiap sampel. Dari situ kita dapat rumuskan nilai E pada setiap sampel dan di dapatkan nilai-nilai yang di butuhkan untuk melanjutkan analisis simulasi pada perhitungan manual dengan menggunakan rumus elastic untuk di lanjutkan dengan rumus penurunan tanah. 


\section{Asumsi denah analisis}

Pada tahap ini kita akan melakukan desain potongan horizontal denah yang di asumsikan dan di hitung manual menggunakan rumus elastik, kita dapat simulasikan perbaikan pada desain yang kita asumsikan. Pada jurnal yang menajadi sumber data penelitian analisis ini di berikan illustrasi simulasi penggunaan alat Centrifuge model test yaitu alat pengujian yang mensimulasikan perbaikan tanah dengan cara pemberian stabilitas struktur tanah dengan memadatkan titik tertentu dan juga kedalaman tertentu. Ilustrasi test tersebut dapat di lihat pada gambar 6 .
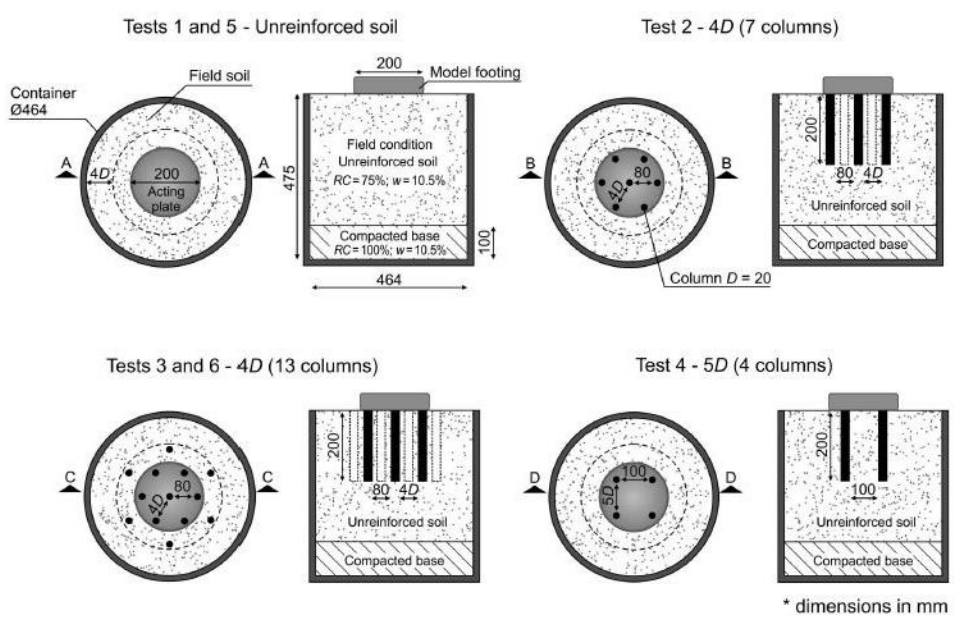

Gambar 6. Illustrasi centrifuge model test dalam lab (Sumber: Pereira, 2019)

Pada fase ini akan dilakukan asumsi luas keseluruhan, banyak kolom, dan diameter kolom tanah yang akan di lakukan dan akan dihitung mengunakan perhitungan manual menggunakan rumus elastic untuk dihitung tiap penurunan contoh parameter yang sudah di lakukan perbaikan dan belum diperbaiki. Dengan ini di dapatkan simulasi langsung pada lapangan pada desain yang kita asumsikan pada perhitungan manual menggunakan rumus elastik. Sesudah itu dilanjutkan dengan perbandingan penurunan pada tanah yang tidak dilakukan perbaikan dan juga tanah yang sudah di lakukan perbaikan dalam simulasi. Yang dilihat adalah adakah perubahan penurunan yang signifikan perbaikan tanah dengan jenis perbaikan Compacted Lateritic Soil Columns pada permukaan tanah dengan dibebanin pembebanan dengan dimensi yang seragam. Ilustrasi tersebut dapat di lihat pada gambar7.
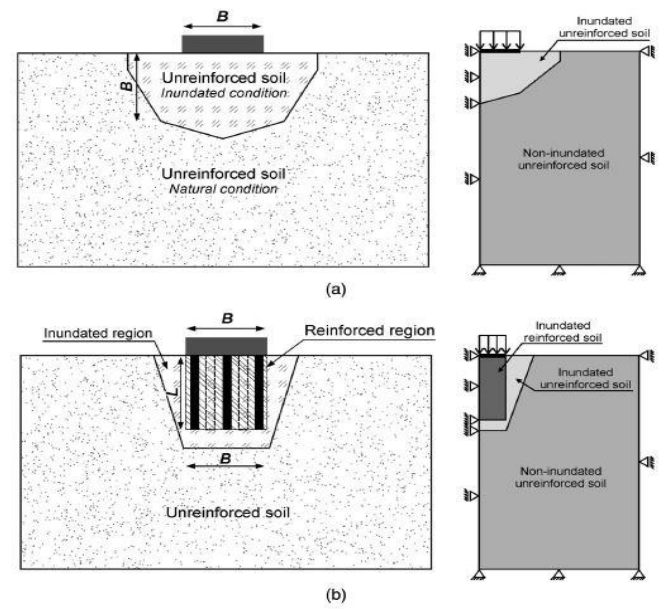

Gambar 7. Illustrasi pengetesan pembebanan pada tanah dengan keadaan unreinforced dan reinforced soil (Sumber: Pereira, 2019)

\section{Analisis hasil akhir}

Analisis hasil akhir dilakukan dengan membandingkan besarnya indeks data keruntuhan yang dihitung dengan rumus perhitungan elastik yang kita masukkan pada potongan asumsi yang di ambil dengan keadaan natural dan tanah yang sudah di stabilisasi dengan cara Compacted Lateritic Soil Columns. Hasil analisis yang kita dapatkan di 
bandingkan ke hasil yang diperoleh jurnal yang digunakan sebagai pedoman apakah perbandingan angka penurunan valid atau tidak. Berikut adalah hasil dari penelitian jurnal yang di teliti pada gambar 8 dan gambar 9 .

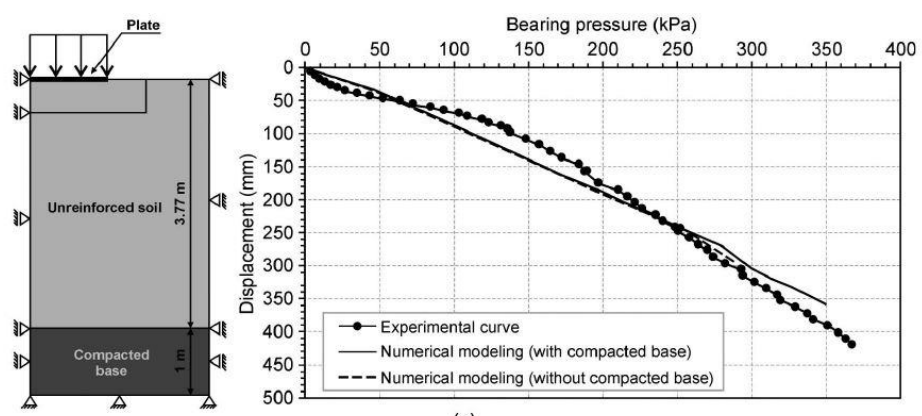

(a)

Gambar 8. Test pembebanan pada tanah yang belum dilakukan perbaikan (Sumber: Pereira, 2019)
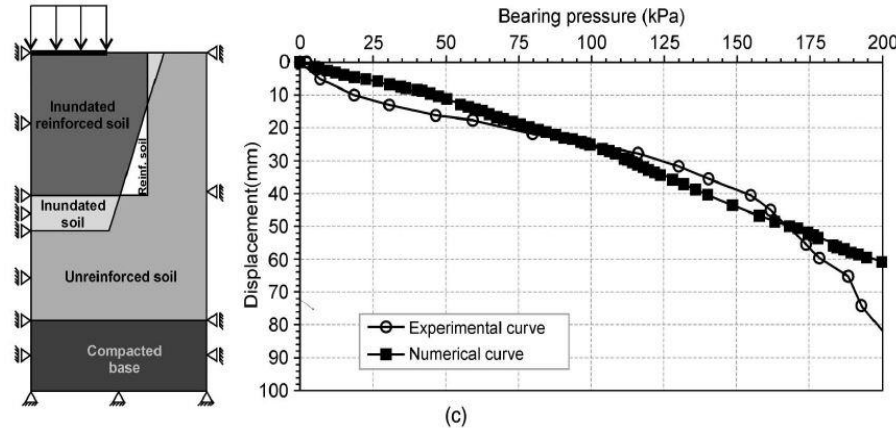

Gambar 9. Test pembebanan terhadap tanah yang sudah di lakukan perbaikan (Sumber: Pereira, 2019)

\section{HASIL DAN PEMBAHASAN}

\section{Karakteristik tanah}

Uji gradasi butiran tanah di atas di simpulkan bahwa komposisi tanah yang diteliti adalah Clayey sandy soil. Dengan ini dapat di jabarkan karakteristik setiap tanah yang akan di gunakan sebagai pebanding parameter yang akan di analisis. Tabel pebanding dapat di lihat pada tabel 1.

Tabel 1. Penjajaran karakteristik tanah

\begin{tabular}{cccc} 
& \multicolumn{3}{c}{ BEDA UJI } \\
\hline UJI LABORATORIUM & SAO & SUMATRA UTARA(Nitta, & TAMILNADU (Sujatha E.R, \\
\hline SPECIFIC GRAVITY & & $2014)$ & 2018 ) \\
\hline Gs & 2,41 & 2,11 & 2,09 \\
ATTERBERG TEST & & & 25,5 \\
Batas Cair, Wl(\%) & 22 & 24,23 & 18,65 \\
Batas Plastis, Wp(\%) & 16 & 14,38 & 6,85 \\
Indeks Plastisitas, Ip(\%) & 6 & 9,85 & 0 \\
GRAIN SIZE (ukuran & & & 20,1 \\
butir) & 2,87 & 0 & 9,78 \\
Gravel(\%) & 26,22 & 29,41 & 70,12 \\
Pasir(\%) & 12,22 & 7,81 & MH \\
Lanau(\%) & 58,69 & 62,78 & \\
Lempung(\%) & & & MH \\
Klasifikasi Tanah & MH & & \\
(USCS) & & & \\
\hline
\end{tabular}




\section{Perhitungan nilai E}

Perhitungan nilai yang akan di gunakan pada perhitungan manual dengan menggunakan rumus elastic ini adalah nilai E yang dapat di peroleh dengan mengerjakan menggunakan rumus modulus elastisitas Young ( 1727) .Dengan rumus ini kita dapat mendapatkan nilai E dari tiap titik pengetesan yang digunakan pada table-tabel nilai Qu. Nilai yang akan di cari adalah nilai E komposit atau Modulus elastisitas gabungan yang di hitung menggunakan rumus

$$
\overline{\mathrm{E}}=\frac{(80 x E 1+20 x E 2)}{100}
$$

Dengan $\overline{\mathrm{E}}=$ Modulus elastisitas Komposit, E1 = Modulus elastisitas Unreinforced, E2 = Modulus elastisitas Reinforced (Dipadatkan 2.5\%).

Dengan ini kita dapat mendapatkan nilai total modulus elastisitas dari setiap parameter yang tercantum pada tabel 2 dan tabel 3.

Tabel 2. Nilai modulus elastisitas parameter jurnal Nitta (2014)

\begin{tabular}{ccc}
\hline E1 & E2 & E komposit \\
\hline 784,532 & 1078,739 & 843,375688 \\
980,665 & 1078,739 & 1000,28267 \\
637,432 & 1078,739 & 725,695451 \\
523,021 & 1078,739 & 634,166377 \\
490,333 & 1274,873 & 647,241959 \\
823,759 & 1732,518 & 1005,5129 \\
898,943 & 1779,216 & 1075,00028 \\
700,475 & 1936,824 & 947,74685 \\
710,982 & 2059,407 & 980,669298 \\
533,918 & 1961,341 & 819,403788 \\
\hline
\end{tabular}

Tabel 3. Nilai modulus elastisitas parameter jurnal Sujatha (2018)

\begin{tabular}{ccc}
\hline E1 & E2 & E komposit \\
\hline 1131,151 & 1621,488 & 1229,22156 \\
1139,969 & 1630,305 & 1238,03939 \\
1142,939 & 1633,275 & 1241,00946 \\
1144,43 & 1634,766 & 1242,50033 \\
1145,326 & 1635,663 & 1243,39674 \\
956,4417 & 1636,261 & 1092,40843 \\
934,6273 & 1636,689 & 1075,04243 \\
961,3618 & 1637,01 & 1096,49433 \\
982,1658 & 1637,26 & 1113,18749 \\
998,8155 & 1637,46 & 1126,54729 \\
\hline
\end{tabular}

\section{Perhitungan nilai edge of displacement (penurunan yang terjadi)}

Perhitungan nilai penurunan yang terjadi pada tanah kita simulasikan dengan tanah yang memiliki karakteristik potensi terjadi nya collapsible soil. Perhitungan analisis ini menggunakan asumsi dengan tanah yang memiliki kadar air dengan variable $90 \%, 80 \%$ dan $60 \%$. Dengan ini kita dapat melihat perbandingan tanah yang memiliki 
modulus elastisitas unreinforced dan tanah yang sudah memiliki modulus elastisitas komposit. Hasil perhitungan total penurunan yang terjadi dapat di lihat pada tabel 4 dan tabel 5.

Tabel 4. Variabel penurunan yang terjadi pada tanah collapsible soil Nitta ( 2014 )

\begin{tabular}{ccc}
\hline Pe tanah terendam $90 \%$ & $\mathrm{E} 1$ & $\overline{\mathrm{E}}$ \\
\hline $50 \mathrm{KPa}$ & 31,32 & 23,81 \\
$60 \mathrm{KPa}$ & 37,53 & 28,62 \\
$70 \mathrm{KPa}$ & 43,81 & 33,41 \\
$80 \mathrm{KPa}$ & 49,98 & 38,13 \\
$90 \mathrm{KPa}$ & 56,31 & 42,94 \\
$100 \mathrm{KPa}$ & 85,12 & 49,51 \\
$120 \mathrm{KPa}$ & 89,97 & 57,22 \\
\hline Pe tanah terendam $80 \%$ & $\mathrm{E} 1$ & $\overline{\mathrm{E}}$ \\
\hline $50 \mathrm{KPa}$ & 15,62 & 11,91 \\
$60 \mathrm{KPa}$ & 18,83 & 14,31 \\
$70 \mathrm{KPa}$ & 21,91 & 16,82 \\
$80 \mathrm{KPa}$ & 24,76 & 18,88 \\
$90 \mathrm{KPa}$ & 28,12 & 21,51 \\
$100 \mathrm{KPa}$ & 41,31 & 25,64 \\
$120 \mathrm{KPa}$ & 47,53 & 28,61 \\
\hline $90 \mathrm{KPa}$ & $\mathrm{E} 1$ & $\overline{\mathrm{E}}$ \\
\hline $100 \mathrm{KPa}$ & 7,81 & 5,98 \\
$120 \mathrm{KPa}$ & 9,44 & 7,21 \\
\hline $60 \mathrm{KPa}$ & 10,93 & 8,32 \\
$70 \mathrm{KPa}$ & 12,51 & 9,52 \\
$80 \mathrm{KPa}$ & 13,96 & 10,73 \\
\hline tana & 21,62 & 13,71 \\
\hline $\mathrm{KPa}$ & 24,82 & 14,32 \\
\hline
\end{tabular}


Tabel 5. Variabel penurunan yang terjadi pada tanah collapsible soil Sujatha ( 2018 )

\begin{tabular}{|c|c|c|}
\hline Pe tanah terendam $90 \%$ & $\mathrm{E} 1$ & $\overline{\mathrm{E}}$ \\
\hline $50 \mathrm{KPa}$ & 20,02 & 18,04 \\
\hline $60 \mathrm{KPa}$ & 24,04 & 21,48 \\
\hline $70 \mathrm{KPa}$ & 27,97 & 24,92 \\
\hline $80 \mathrm{KPa}$ & 32,01 & 28,72 \\
\hline $90 \mathrm{KPa}$ & 35,98 & 32,33 \\
\hline $100 \mathrm{KPa}$ & 62,89 & 37,73 \\
\hline $120 \mathrm{KPa}$ & 64,01 & 37,96 \\
\hline Pe tanah terendam $80 \%$ & E1 & $\overline{\mathrm{E}}$ \\
\hline $50 \mathrm{KPa}$ & 10,23 & 8,87 \\
\hline $60 \mathrm{KPa}$ & 11,88 & 10,82 \\
\hline $70 \mathrm{KPa}$ & 14,04 & 12,51 \\
\hline $80 \mathrm{KPa}$ & 15,78 & 14,34 \\
\hline $90 \mathrm{KPa}$ & 18,01 & 16,13 \\
\hline $100 \mathrm{KPa}$ & 35,99 & 19,72 \\
\hline $120 \mathrm{KPa}$ & 38,22 & 21,51 \\
\hline Pe tanah terendam $60 \%$ & E1 & $\overline{\mathrm{E}}$ \\
\hline $50 \mathrm{KPa}$ & 5,12 & 4,51 \\
\hline $60 \mathrm{KPa}$ & 6,04 & 5,43 \\
\hline $70 \mathrm{KPa}$ & 7,12 & 6,33 \\
\hline $80 \mathrm{KPa}$ & 8,03 & 7,22 \\
\hline $90 \mathrm{KPa}$ & 9,05 & 8,14 \\
\hline $100 \mathrm{KPa}$ & 16,12 & 10,81 \\
\hline $120 \mathrm{KPa}$ & 17,79 & 11,8 \\
\hline
\end{tabular}

\section{Grafik hasil perhitungan}

Dari penjajaran tabel di atas dapat di gambarkan pada design grafik yang menunjukan terjadinya collapsible soil pada tekanan $100 \mathrm{KPa}$. Nilai PE1 adalah nilai perhitungan yang di ambil dari contoh tanah yang belum di lakukan stabilitas menggunakan metode compacted lateritic soil columns dan nilai $\mathrm{PE}$ adalah perhitungan yang menggunakan tanah dengan keadaan sudah di lakukan stabilitas dengan metode compacted lateritic soil columns. Grafik collapsible soil dapat di lihat pada gambar 10,11,12,13,14, dan 15. 


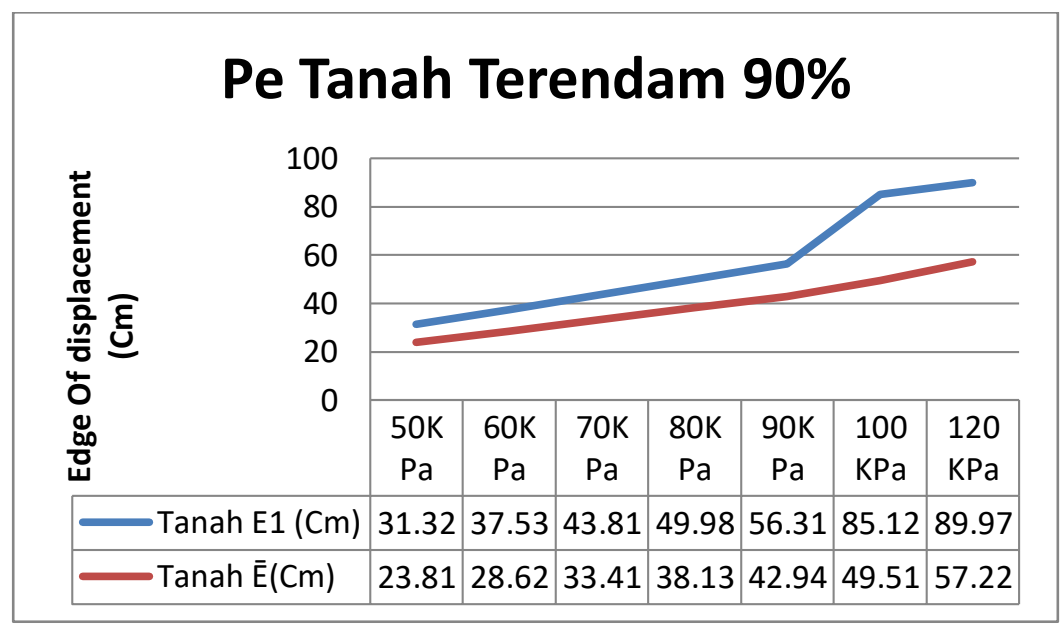

Gambar 10. Grafik collapsible soil pada variabel tanah terendam 90\%, Nitta (2014)

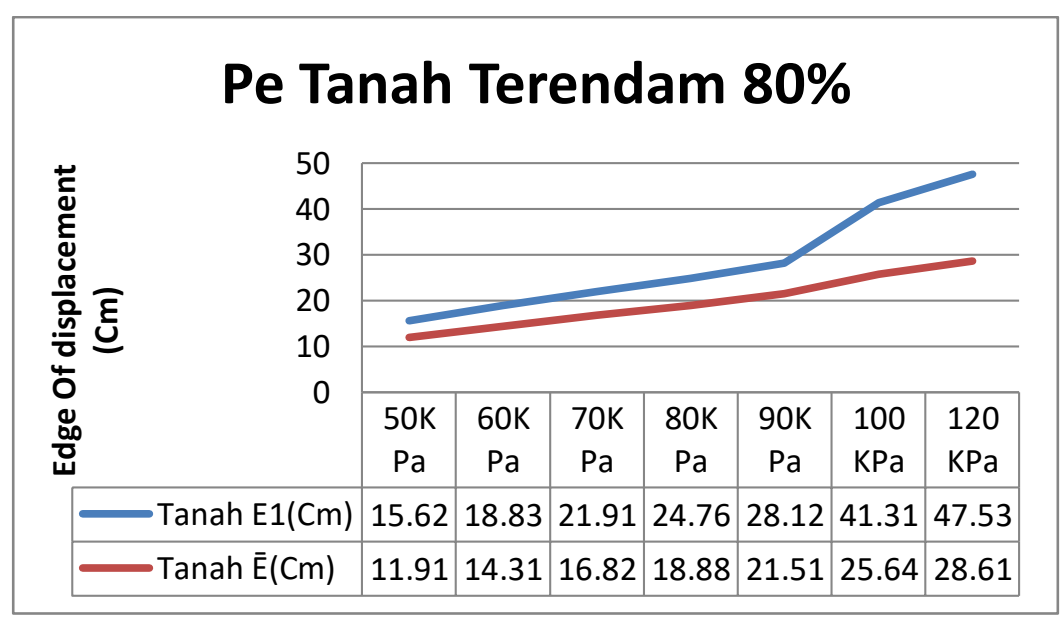

Gambar 11. Grafik collapsible soil pada variabel tanah terendam 80\%, Nitta (2014)

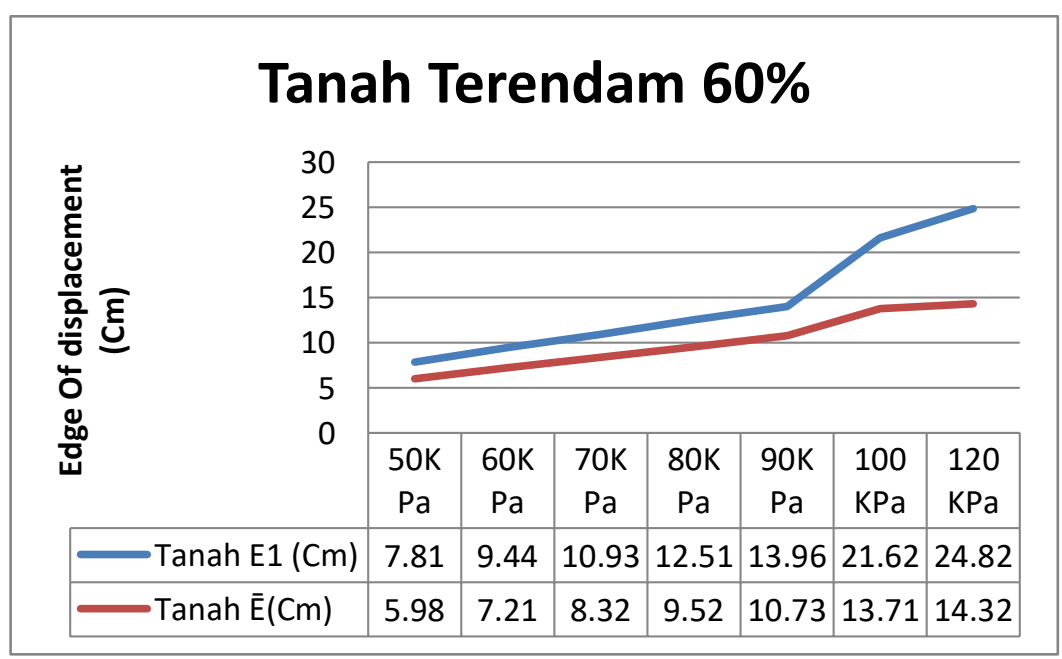

Gambar 12. Grafik collapsible soil pada variabel tanah terendam 60\%, Nitta (2014) 


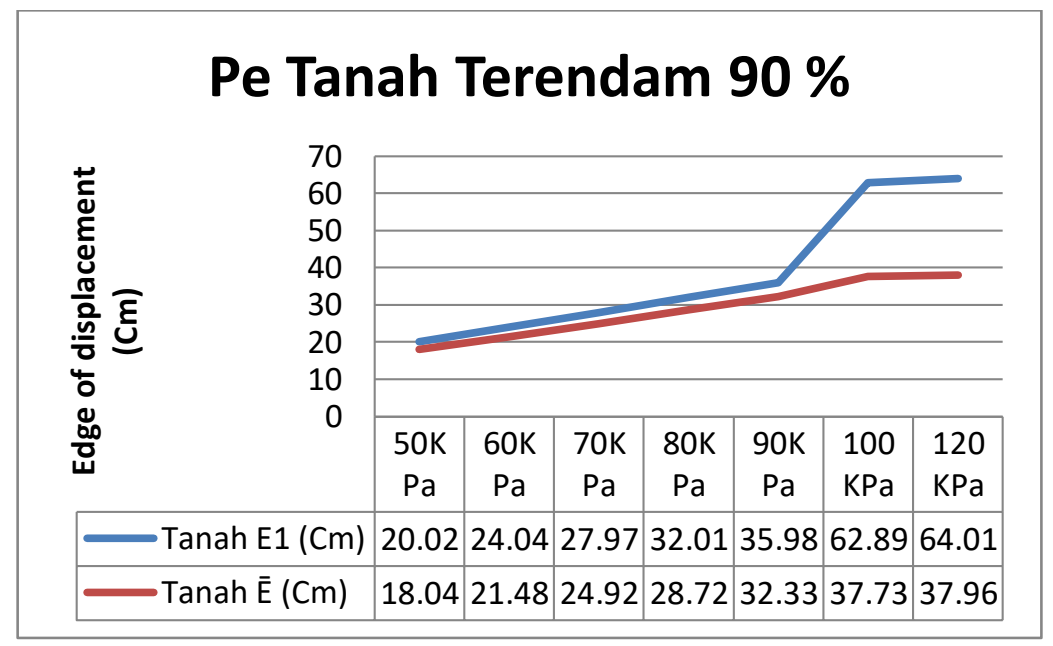

Gambar 13. Grafik collapsible soil pada variabel tanah terendam 90\%, Sujatha (2018)

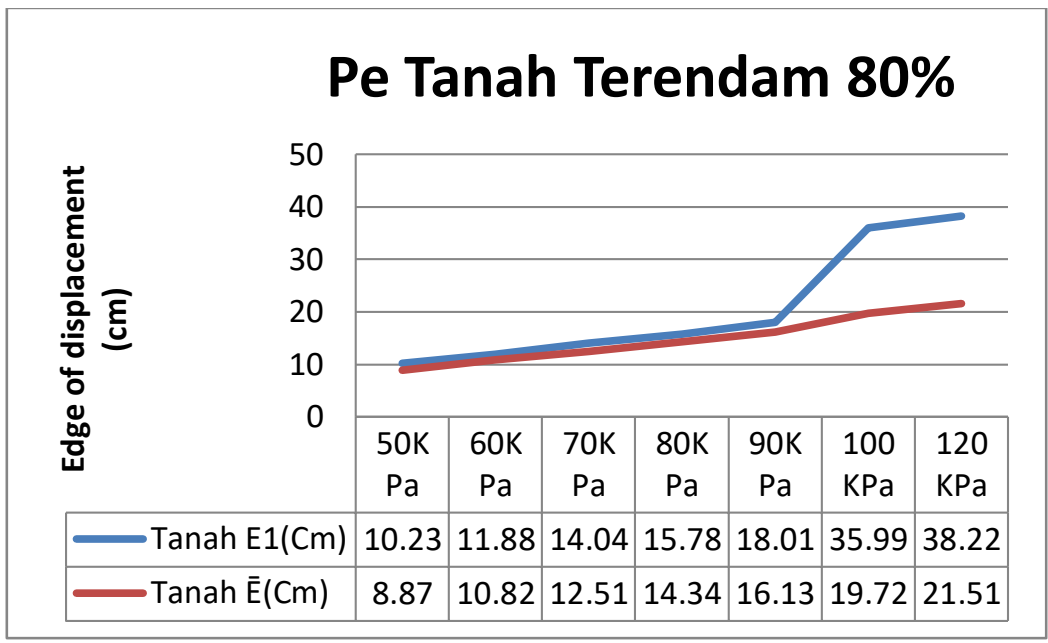

Gambar 14. Grafik collapsible soil pada variabel tanah terendam 80\%, Sujatha (2018)

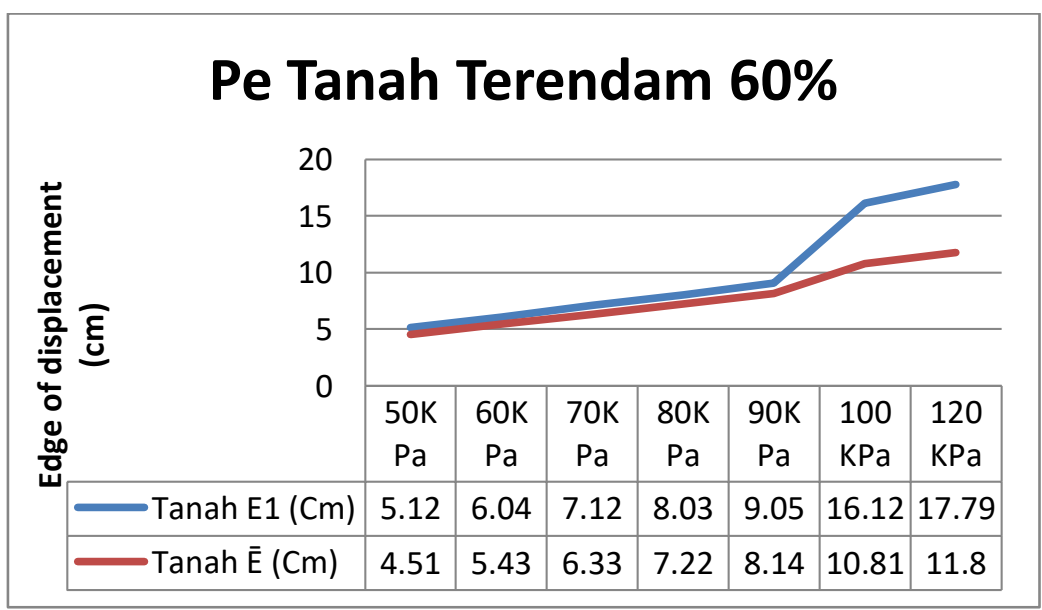

Gambar 15. Grafik collapsible soil pada variabel tanah terendam 60\%, Sujatha (2018) 
Grafik selanjutnya adalah grafik yang menunjukan hubungan antara defleksi dengan modulus elastisitas tanah yang dapat di lihat pada gambar 16 dan 17.

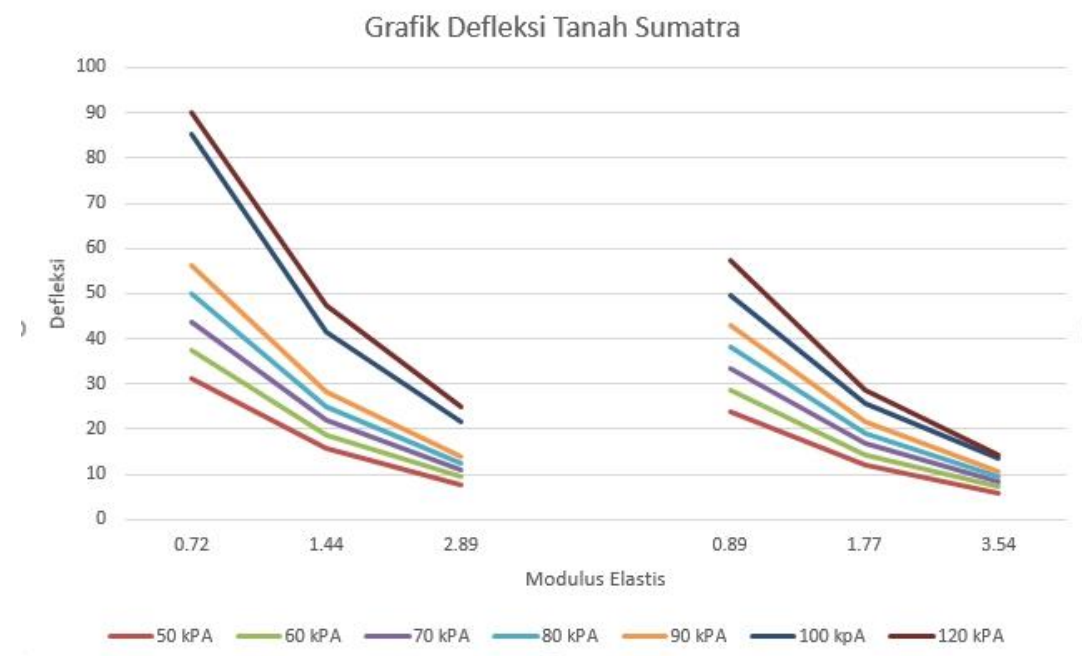

Gambar 16. Grafik hubungan defleksi dengan modulus elastisitas, Nitta (2014)

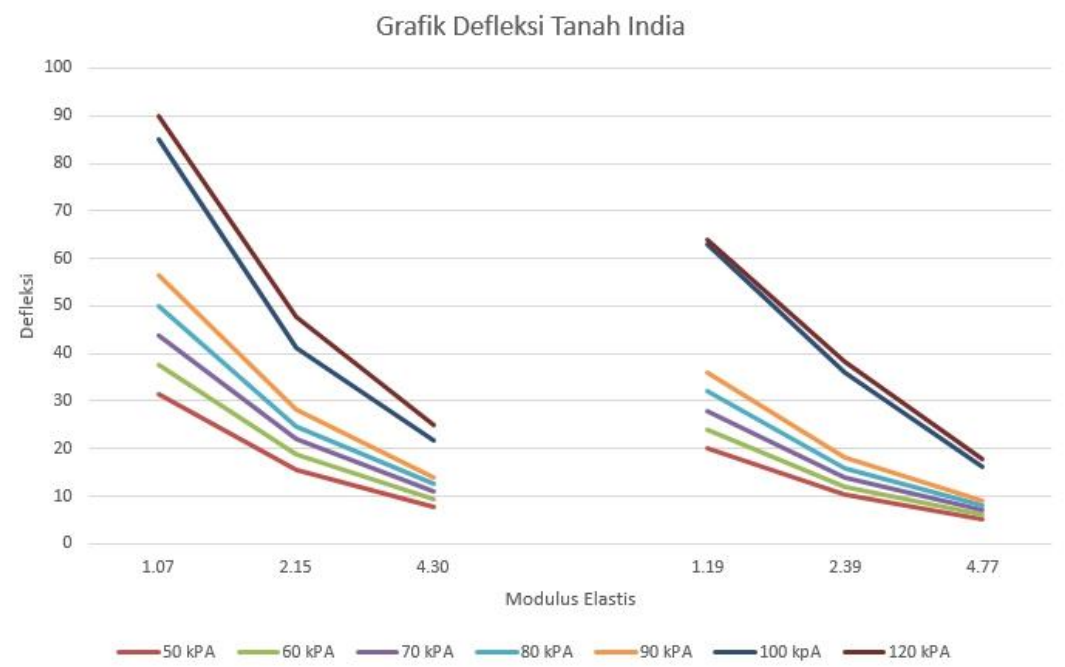

Gambar 17. Grafik hubungan defleksi dengan modulus elastisitas, Sujatha (2018)

\section{KESIMPULAN DAN SARAN}

\section{Kesimpulan}

Bedasarkan hasil analisi ulang yang di lakukan bedasarkan penelitian yang di lakukan oleh Pereira, Mara Sarro (2018) yang melakukan stabilitas tanah bersifat collapsible soil dengan menggunakan Compacted lateritic soil columns atau dapat di sebut stabilitas tanah menggunakan kolom tanah padat. Jurnal tersebut melakukan praktik langsung di dalam lab untuk mengetahui perubahan yang terjadi yang di akibatkan stabilitas tersebut. Analisis ulang ini tidak melakukan test di dalam lab melainkan perhitungan ulang dengan data asumsi yang di tentukan dan dilandasi oleh standart yang berlaku. Analisis ulang ini menggunakan 2 data parameter tanah yang di ambil dari jurnal penelitian milik Nitta,Fadillah (2014) yang membahas stabilitas tanah dengan menggunakan semen Portland dan sekam gandum dan juga jurnal milik Sujatha, E.R (2018) yang membahas stabilitas tanah dengan menggunakan fiber sasil.Alasan penggunakan parameter tanah sebagai pebanding analisis ulang ini di karenakan, 
karakteristik tanah yang dimiliki 2 contoh tanah yang di bahas pada jurnal tersebut memiliki kesamaan dengan karakteristik tanah yang di bahas pada jurnal yang di tulis oleh Pereira,Mara Sarro (2018).

1. Jurnal yang di gunakan tersebut tidak memiliki keadaan tanah yang berpotensi collapsible. Karena itu di lakukan asumsi tanah dengan variable perendaman air sebesar 90\%, 80\%, dan 60\%. Cara stabilitas dengan menggunakan Compacted lateritic soil columns di hitung dengan cara mencari nilai E komposit atau keadaan tengah di mana komposisi modulus elastis tanah unreinforced di beri kekuatan tanah yang sudah di lakukan pemadatan sebesar 2.5\%. E komposit akan di bandingkan dengan E Unreinforced dengan keadaan tanah terendam air variable $90 \%, 80 \%$, dan $60 \%$.

2. Pada perhitungan total pembahasan bab 4 di buktikan bahwa, stabilitas tanah menggunakan Compacted lateritic soil columns mengurangi kemungkinan terjadi nya Collapsible pada tanah dengan keadaan terendam dan memiliki kemungkinan terjadi collapsible soil atau penurunan tanah secara mendadak Dan di dapatkan penurunan yang mendadak pada penekanan di angka 90KPa menuju penekanan sebesar 100 $\mathrm{KPa}$ dan mengalami kestabilan penurunan pada nilai penekanan $120 \mathrm{KPa}$.

\section{Saran}

Dari hasil analisi ulang yang di lakukan asumsi yang di gunakan bukan lah nilai pasti atau data lab yang valid. Di sarankan penggunaaan data lab yang lengkap dan juga data borlog agar analisis menghasilkan hasil yang lebih valid di banding analisis ulang yang menggunakan data asumsi dengan parameter dari jurnal-jurnal yang hanya di tentukan dari kemiripan karakateristik tanah yang di miliki. Penggunaan stabilitas tanah ini juga dapat di katakana memiliki umur yang singkat di bandingkan penggunaan pile cap atau beberapa jenis stabilitas tanah yang memiliki struktur kaku. Dikarenakan pemadatan tanah dalam bentuk kolom jika mengalami ganguan cuaca atau rendaman air berskala waktu lama. Akan terjadinya perubahan sifat kolom tanah padat yang sudah di padatkan dan dapat terjadinya penurunan daya dukung kolom tanah dikarenakan perubahan lingkungan yang terjadi di sekitarnya.

\section{DAFTAR PUSTAKA}

Fadillah, Nitta. "Pengujian Tekan Beban (Unconfined Compression Test) Pada Stabilitas Tanah Lempung Dengan Campuran Semen Dan Abu Sekam Padi." (2014).

Gibbs dan Bara. "Susceptibility to Collapse." (1962).

Pereira, Mara Sarro. "Performance Evaluation of a Collapsible Soil Reinforced with Compacted Lateritic Soil Columns.” (2019).

Rollins, Kyle dan Wayne Rogers. "Mitigation Measures For Small Structures on Collapsible Alluvial Soils." (1995).

Sujatha. "Influence of Random Inclusion of Treated sisal Fibres on The Unconfined Compressive Strength of Highly Compressible Clay." (2018).

Surachri. " Stabilitas Tanah Collapsible Soil Menggunakan Metode Penggunaan Bahan Geotextile." Untar. 2018.

Nuary, M Guruh. "BNPB: 40,9 Juta Jiwa Tinggal Di Daerah Rawan Longsor.” Detiknews, Detik, 3 Jan. 2019 , m.detik.com/news/berita/d-4368875/bnpb-409-juta-jiwa-tinggal-di-daerah-rawan-longsor.

Jono, Syafei. "Penurunan Tanah Collapsible soil dengan Variant Kepadatan kering 95\% dan 98\%"(2017) 